\title{
Action of pancreozymin preparations on gastric acid secretion ${ }^{1}$
}

\author{
M. NAKAMURA, ${ }^{2}$ S. NAKAJIMA, AND D. F. MAGEE \\ From the Departments of Physiology and Pharmacology, Creighton University School of Medicine, \\ Omaha, Nebraska, U.S.A.
}

It was reported that commercial preparations of both secretin and pancreozymin inhibit gastric acid secretion (Greenlee, Longhi, Guerrero, Nelsen, El-Bedri, and Dragstedt, 1957; Gillespie and Grossman, 1964). Pancreozymin (PZ), in addition, inhibits gastric motility (Johnson and Magee, 1965). Magee and Nakamura (1966), in a preliminary report, have noted that gastric acid is inhibited readily in conscious dogs only when large doses of PZ are used. With small doses, on the contrary, gastric acid secretion is stimulated.

\section{METHODS}

Fifteen dogs were used. Of these four had simple gastric fistulae. Four had innervated fundic pouches of the type of Dragstedt, Woodward, Storer, Oberhelman, and Smith (1950). Eight had double pouches made from the whole denervated stomach. The antrum was separated from the fundus by a mucosal septum (Fig. 1). The fundic pouch was, therefore, of the Heidenhain type.

Experiments were started after the animals had recovered and were eating normally. All the drugs and preparations used, except acetylcholine, were given by constant intravenous infusion. The pancreozymin preparations were obtained both from Professor E. Jorpes of the Karolinska Institutet, Stockholm (250 units $/ \mathrm{mg}$ ) and from Boots and Co. Nottingham, England. ${ }^{3}$ A small quantity of the Jorpes (Jorpes and Mutt, 1966) PZ was of a very high purity (1,500 units/mg), and experiments with this are indicated in the tables. The synthetic gastrin pentapeptide was that of Imperial Chemical Industries. ${ }^{4}$ Other gastric secretory stimulants used were methacholine, histamine, feeding, and antral irrigation with acetylcholine. In the experiments with histamine, gastrin pentapeptide, and methacholine a dose response curve for gastric acid secretion was obtained and then repeated with background $\mathrm{PZ}$. In the methacholine experiments both varying PZ and background methacholine and background $\mathrm{PZ}$ with varying

'Supported by grant Am 10285-02 from the National Institutes of Health.

${ }^{2}$ Present address: Department of Medicine, Nagoya University Hospital, Nagoya, Japan.

${ }^{3}$ Throughout units are expressed as Ivy dog cholecystokinin units. "Kindly supplied through Dr D. Fitzgerald of ICI by Ayerst Laboratories. methacholine were tried. Differences between the respective curves were analysed statistically. The two curves, before and after, were always obtained on the same day. For each curve the doses were given in random order. In the feeding and antral irrigation experiments, $\mathbf{P Z}$ was given after a steady response had been obtained.

Acid was titrated to $p \mathrm{H} 7$ using the Radiometer titrator.

In the experiments with gastrin pentapeptide, histamine, and feeding, only double-pouch animals were used. In the methacholine experiments simple gastric fistula and innervated fundic pouch animals were added.

RESULTS

The results with varying doses of methacholine with

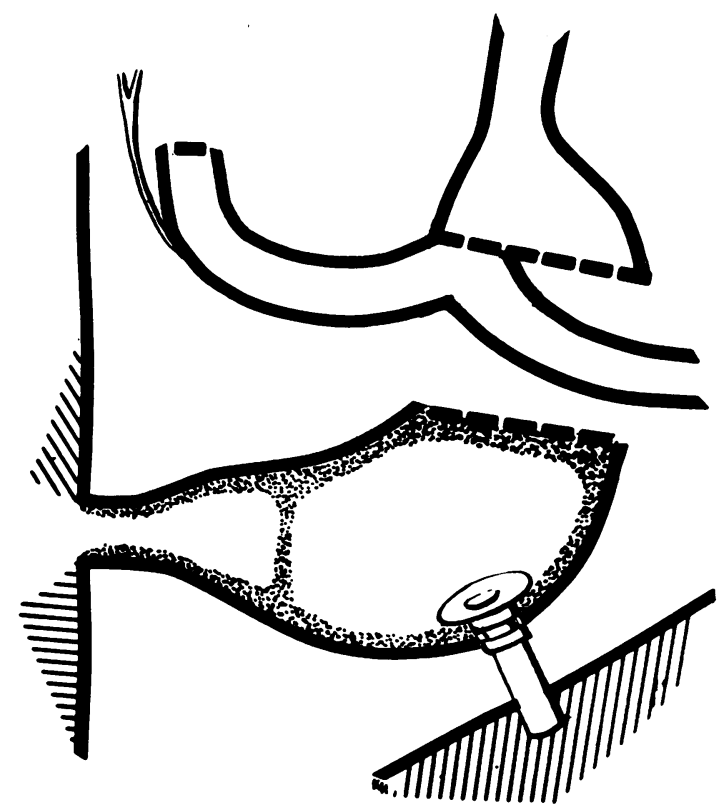

FIG. 1. The double pouch preparation. The mucosa is stippled. 
TABLE I

EFFECT OF INCREASING DOSE OF METHACHOLINE ON GASTRIC ACID SECRETION (M-EQUIV/5 MIN) WITH AND WITHOUT BACKGROUND PANCREOZYMIN IN DOGS

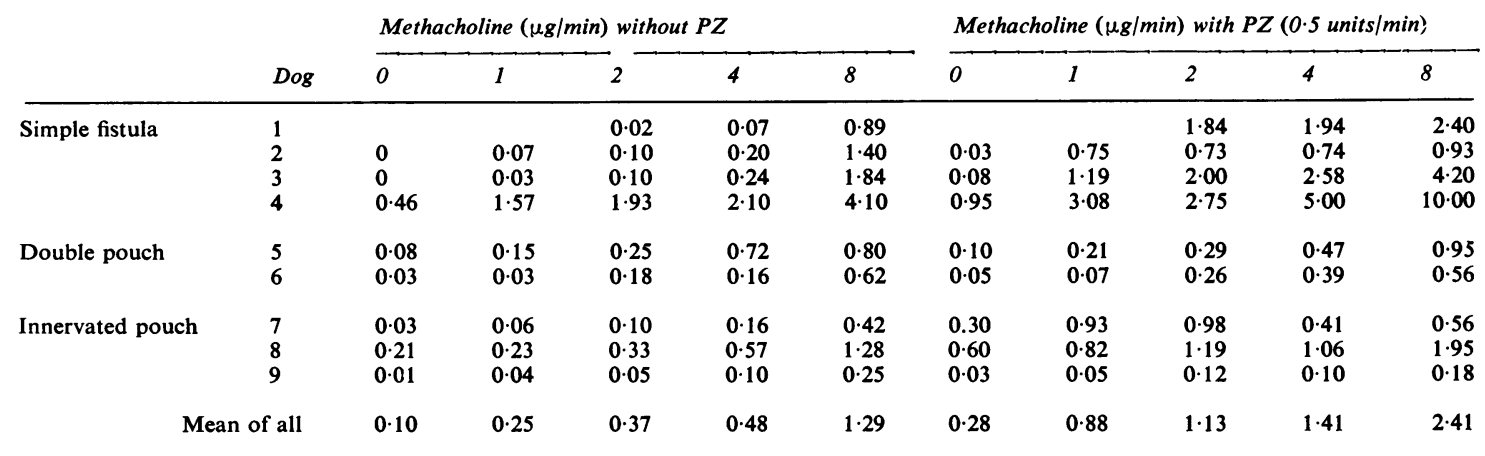

TABLE II

EFFECT OF INCREASING DOSES OF PANCREOZYMIN ON GASTRIC ACID SECRETION (M-EQUIV/5 MIN) IN DOGS WITH AND WITHOUT BACKGROUND METHACHOLINE

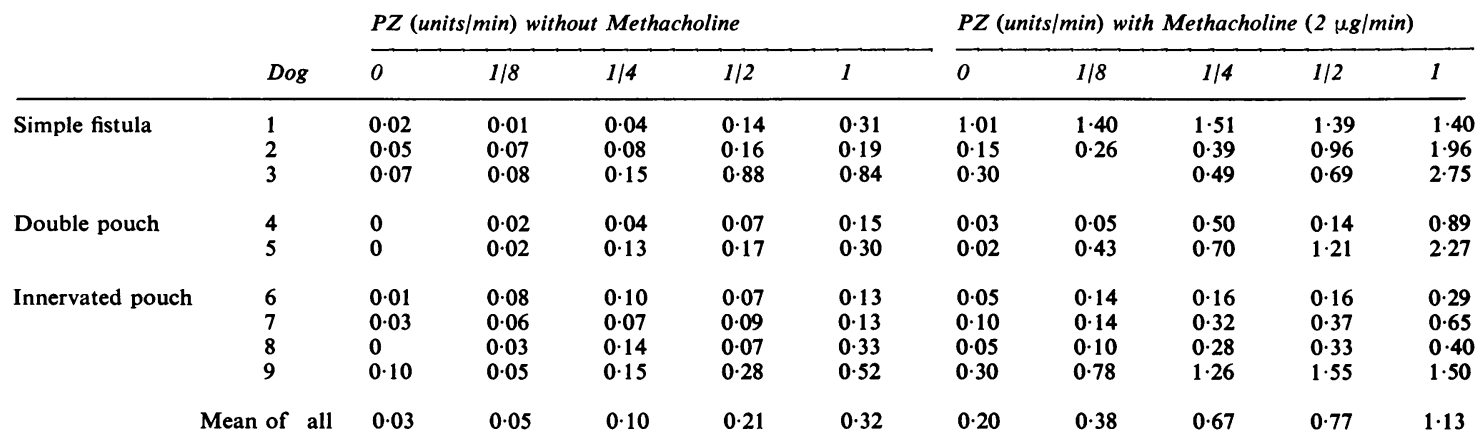

TABLE IIa

EFFECT OF INCREASING DOSES OF BOOTS PZ WITH BACKGROUND METHACHOLINE $(8 \gamma / \mathrm{MIN})$ ON GASTRIC ACID (M-EQUIV/5 MIN)

\begin{tabular}{|c|c|c|c|c|}
\hline \multirow[b]{2}{*}{ Dog } & \multicolumn{4}{|c|}{$P Z$ (units/min) } \\
\hline & 0 & $1 / 4$ & $1 / 2$ & 1 \\
\hline 1 & 0.80 & $1 \cdot 12$ & 0.95 & 0.85 \\
\hline 2 & $4 \cdot 10$ & $4 \cdot 50$ & 10.00 & $8 \cdot 20$ \\
\hline $\begin{array}{l}3 \\
4\end{array}$ & $\begin{array}{l}3.60 \\
0.62\end{array}$ & $\begin{array}{l}1.80 \\
1.01\end{array}$ & $\begin{array}{l}4.20 \\
0.56\end{array}$ & $\begin{array}{l}4.30 \\
0.24\end{array}$ \\
\hline $\begin{array}{l}4 \\
5\end{array}$ & $\begin{array}{l}0.62 \\
0.25\end{array}$ & $\begin{array}{l}1.01 \\
0.17\end{array}$ & 0.56 & \\
\hline 6 & 0.25 & $\begin{array}{l}0.17 \\
0.42\end{array}$ & $\begin{array}{l}0.31 \\
0.63\end{array}$ & 0.43 \\
\hline
\end{tabular}

and without a background infusion of pancreozymin are shown in Table I. At every dose of methacholine the acid secretion was higher with PZ than without it, with the exception of one doublepouch animal at $4 \mu \mathrm{g} / \mathrm{min}$ and one at $8 \mu \mathrm{g} / \mathrm{min}$, one innervated pouch animal at 4 and $8 \mu \mathrm{g} / \mathrm{min}$, and one simple fistula at $8 \mu \mathrm{g} / \mathrm{min}$.

In the experiments with varying PZ and background methacholine (Table II), with only one exception (dog 3, 0.5 units $\mathrm{PZ} / \mathrm{min}$ ), secretion was greater with background methacholine than without, but even here in a few cases the differences were greater with low doses of PZ than with high.

The data in Tables I and II satisfy Bartlett's test for homogeneity. The results in each separately were, therefore, amalgamated and from them the regression lines in Figs. $2 a$ and $2 b$ were calculated. The differences between the acid secretions at each level are significantly greater for the combined injections than for either one alone except as expected at the highest doses of methacholine (Fig. 2). At this dose in several animals the secretion rates were smaller than those of the corresponding controls. At dose levels at or below $8 \mu \mathrm{g}$ methacholine/min the response to the combined injection was greater than the sum of the responses to either one alone.

In a number of instances $\mathrm{PZ}$ was varied and $8 \mu \mathrm{g} / \mathrm{min}$ of methacholine as background given. Secretion was lower at 1 unit $\mathrm{PZ} / \mathrm{min}$ than at 


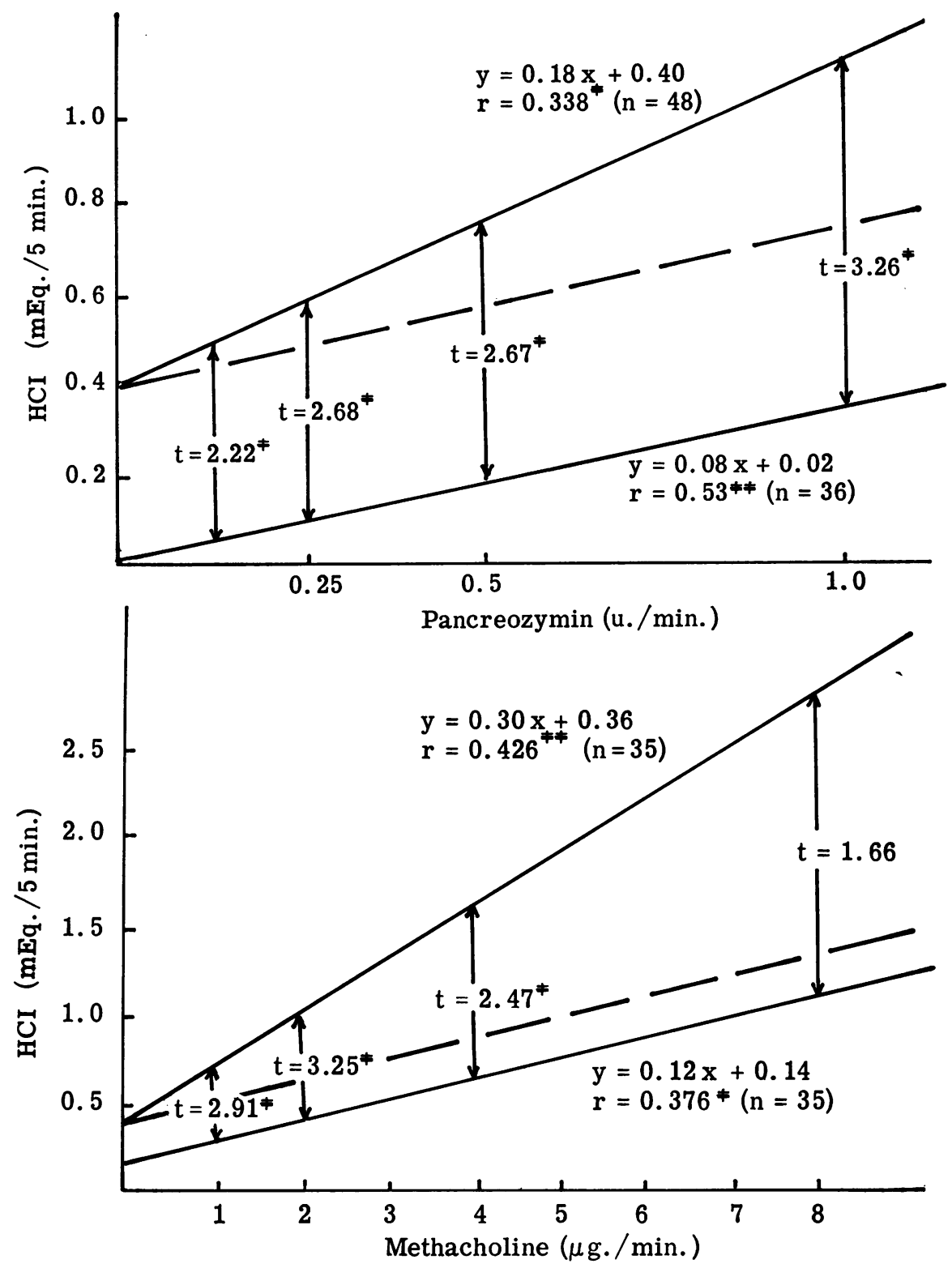

FIG. 2a. Calculated regression lines showing the dose response relationship between PZ and gastric acid with (uppermost curve) and without (lowest curve) background methacholine $2 \mu \mathrm{g} / \mathrm{min}$ in the same nine dogs. The dashed calculated curve shows $P Z$ alone plus the response to $2 \mu \mathrm{g}$ methacholine/min alone. This is the curve expected of an additive response. The mean acid response at 0.25 and 1 units $P Z /$ min with background methacholine is significantly more than additive; $t=2.79(\mathrm{P}<0.01)$ and $2.27(\mathrm{P}<0.05)$ respectively.

FIG. 2b. Calculated regression lines showing the dose response relationship between methacholine and gastric acid secretion with (upper curve) and without (lowest curve) background PZ $(0.5$ units/min intravenously) in the same nine dogs. The calculated dashed curve shows the response to methacholine alone plus that to 0.5 units of $P Z$ when given alone. This is the curve expected of an additive response. The mean response at $1 \mathrm{\mu g}$ methacholine/min with background PZ is significantly more than additive: $t=2.46(\mathrm{P}<0.05)$. 
TABLE III

EFFECT OF HIGHLY PURIFIED (1,500 DOG UNITS/MG) JORPES AND MUTT PANCREOZYMIN ON GASTRIC ACID (M-EQUIV/5 MIN) FROM DOG HEIDENHAIN POUCHES WITH BACKGROUND METHACHOLINE

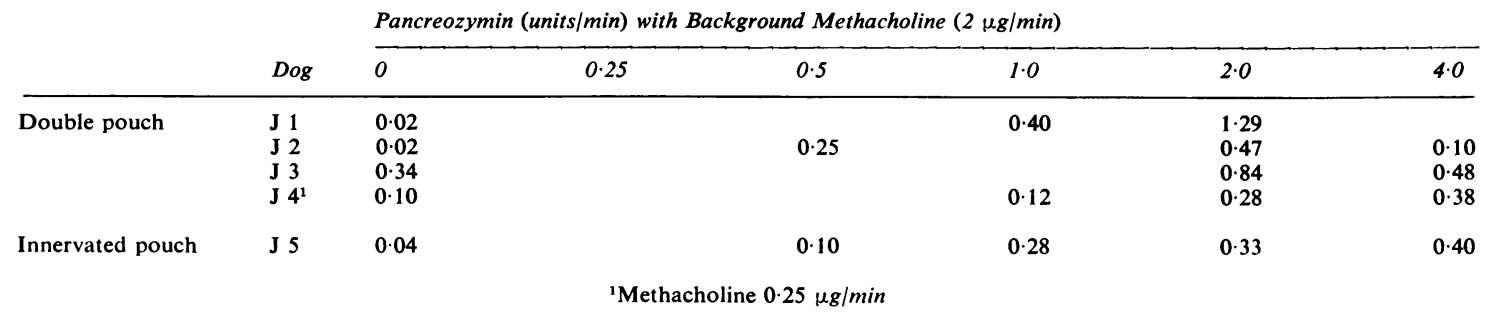

0.5 units. The decrease from 0.5 units to 1.0 unit of $\mathrm{PZ}$ in six dogs with $8 \mu \mathrm{g} / \mathrm{min}$ of methacholine as background is shown in Table IIa.

The results of experiments with Jorpes's preparation (Table III) are substantially the same as those with the Boots preparation. Here also in some animals secretion declined at the highest dose of PZ.

FEEDING In four double-pouch animals, gastric acid secretion was stimulated by feeding $100 \mathrm{~g}$ of meat every $30 \mathrm{~min}$. In this preparation the stimulus to gastric acid can only be intestinal in origin (Fig. 1). Under these conditions, both PZ preparations depressed secretion (Fig. 3).

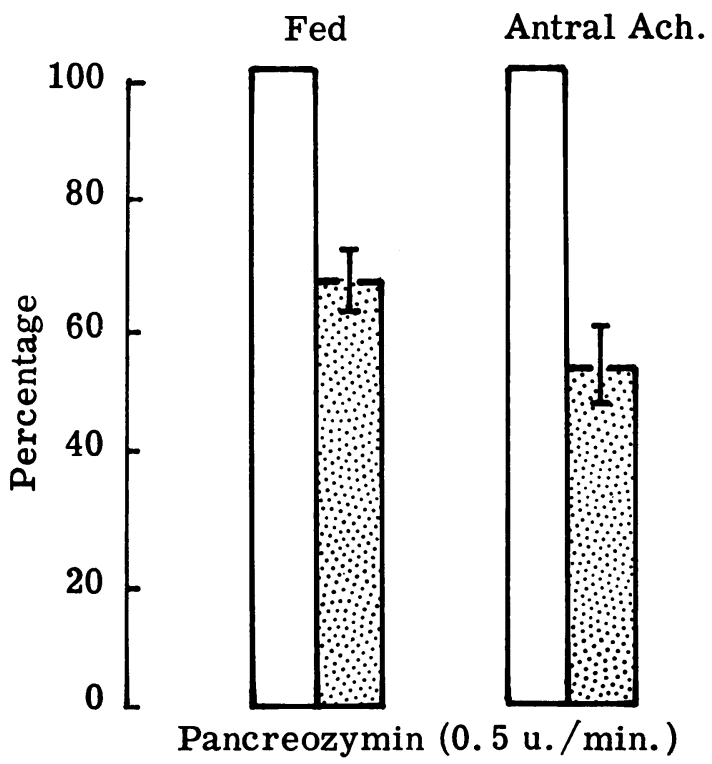

FIG. 3. The percentage change and standard error in gastric acid secretion following intravenous infusion of Jorpes PZ (0.5 unit/min) to double-pouch dogs in which secretion was stimulated by feeding (intestinal phase, four dogs) or by acetylcholine solution $(5 \mathrm{mg} / \mathrm{ml})$ placed in the antral pouch (gastric phase, four dogs).
ANTRAL STIMULATION In three double-pouch animals gastric secretion was stimulated by placing various concentrations of acetylcholine in the antral pouch. The secretory response was significantly depressed by 0.5 units/min of both $\mathrm{PZ}$ preparations (Fig. 3). This is in accord with the results of Brown and Magee (1957).

GASTRIN PENTAPEPTIDE In four double-pouch animals dose response curves for acid secretion in response to gastrin pentapeptide with and without background $\mathrm{PZ}(0.5$ units $/ \mathrm{min})$ were constructed (Fig. 4a). In every case, at doses of pentapeptide above $0.25 \mu \mathrm{g} / \mathrm{min}$, acid secretion was significantly depressed by both Jorpes and Boots PZ.

HISTAMINE In the same four double-pouch animals it was found that the response to histamine was depressed by background PZ compared with the controls (Fig. 4b).

\section{DISCUSSION}

The evidence presented shows that both highly purified (Jorpes) and less purified (Boots) PZ depressed gastric acid secretion evoked by endogenous antral gastrin (acetylcholine in the antral pouch) by stimulating the intestinal phase of gastric secretion (feeding), by histamine, and by gastrin pentapeptide.

Gastric acid secretion was stimulated by intravenous $\mathrm{PZ}$ when given alone. This has been recorded by Murat and White (1966) but not by Preshaw and Grossman (1965) using large single injections of PZ. In their hands the same dose, 75 units/dog, given subcutaneously stimulated gastric acid secretion. Gastric acid was greatly stimulated when pancreozymin was given with low doses of methacholine.

It is now well known that vagal stimulation (Maung Pe Thein and Schofield, 1959) and cholinergic agents in the antrum (Robertson et al, 1950) release gastrin. Pevsner and Grossman (1955) 

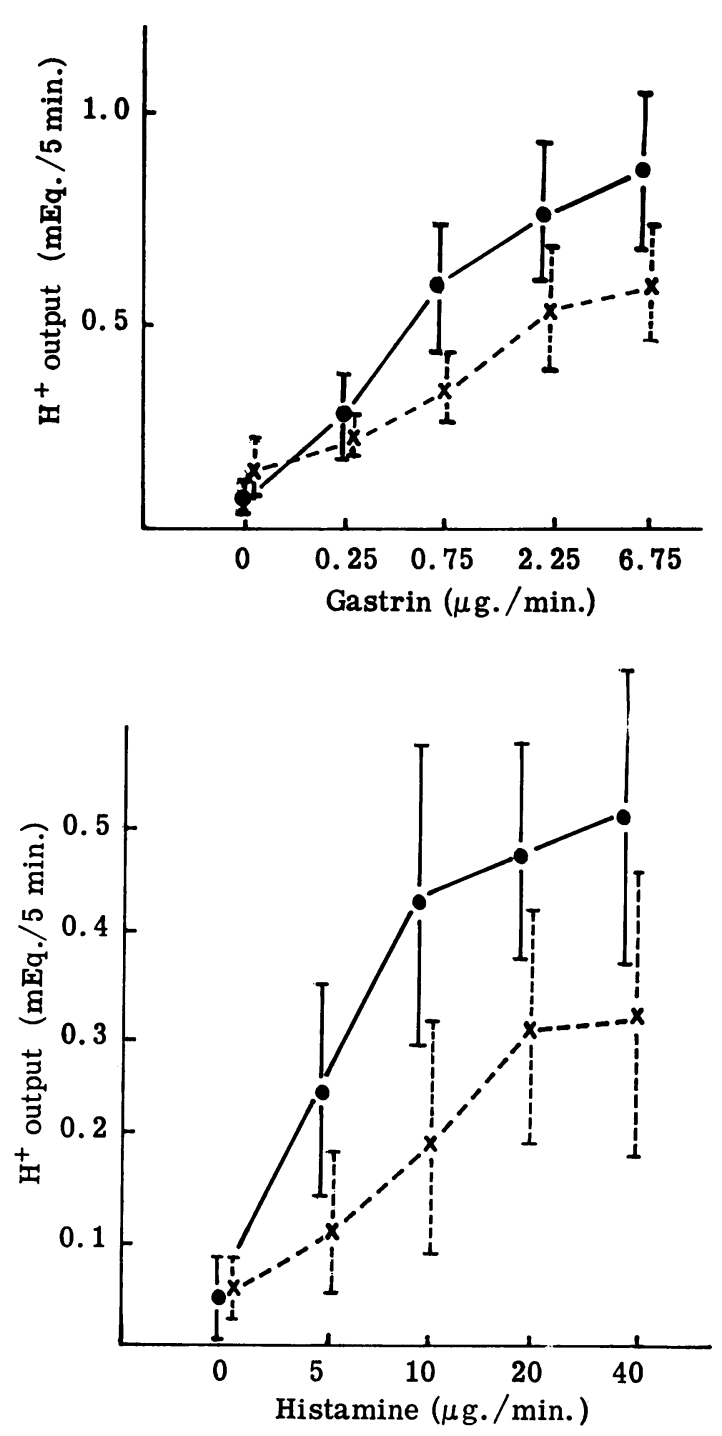

FIG. 4. Dose response curves with standard errors plotted from group means for gastric acid stimulated by gastrin pentapeptide with and without Jorpes $P Z$ $(0 \cdot 5$ unit/min $) A$ in five dogs, and by histamine with and without Jorpes $P Z(0.5$ unit/min) $B$ in five dogs.

The paired differences (before minus after $P Z$ in each dog) were analysed and found to be significant at each dose level in the histamine experiment, and above $0.25 \mu \mathrm{g} / \mathrm{min}$ of the pentapeptide at the $99 \%$ level.

$P Z O$

$\mathrm{X} \ldots \mathrm{X} P Z 0.5 \mu / \mathrm{min}$

have shown that acetylcholine will act directly on the fundic glands. A possible explanation, therefore, for the inhibition seen when the dose of methacholine was increased during simultaneous administration with PZ is that with large doses of methacholine a significant part of the acid response may be due to release of gastrin from the antrum and it is this which was inhibited by PZ whereas low doses of methacholine acted directly on the parietal cells and were augmented by PZ.

Recent studies by Mutt and Jorpes (1967) have indicated that the $C$ terminal pentapeptides of both PZ and gastrin are identical. This may explain the stimulation of gastric acid by $\mathrm{PZ}$ given alone since the terminal pentapeptide is the active part of the gastrin molecule. The purified Jorpes and Mutt preparation used contains no antral gastrin (Jorpes, 1966). This raises the interesting possibility that gastrin and PZ may act competitively but this notion was rendered less attractive by the finding that PZ also depressed histamine-stimulated secretion. If histamine is an obligatory intermediate between stimulus and parietal cell, as has been suggested (Code, 1956), the picture would be clearer, since if PZ interferes with the action of histamine on the parietal cell it will then block all stimuli which act via histamine. Methacholine, which perhaps acts directly at low doses, would not be but would in fact be augmented unless doses high enough to release gastrin were given. There is, however, no real evidence that histamine is an obligatory physiological mediator in the dog and we have not been able to demonstrate that PZ has antihistamine activity on the guinea pig ileum.

The present data add substance to the idea already advanced (Johnson and Magee, 1965) that PZ either is or contains enterogastrone. In small doses it is a potent inhibitor of gastric acid secretion of hormonal origin, and a potent inhibitor of motility in the denervated stomach. Physiologically released enterogastrone has both these properties (Ewald and Boas, 1886). However, physiologically released enterogastrone, according to Gregory and Tracy (1959), will not antagonize either intravenous cholinergic stimuli or histamine.

\section{SUMMARY}

In dogs with gastric fistulae and denervated fundic pouches it was found that pancreozymin and methacholine given together produced greater gastric acid secretion than the sum of their separate responses. As the dose of methacholine was increased above $2 \mu \mathrm{g} / \mathrm{min}$ potentiation disappeared.

Pancreozymin depressed the gastric acid response to the synthetic gastrin pentapeptide, to histamine, to the antral phase of secretion, and to the intestinal phase. 


\section{REFERENCES}

Brown, J. C., and Magee, D. F. (1967). Inhibitory action of cholecystokinin on acid secretion from Heidenhain pouches induced by endogenous gastrin. Gut, 8, 29-31.

Code, C. F. (1956). Histamine in gastric mucosa. In Ciba Foundation Symposium Histamine, edited by G. E. W. Wolstenholme and C. M. O'Connor. p. 195, Churchill, London.

Dragstedt, L. R., Woodward, E. R., Storer, E. H., Oberhelman, H. A., Jr, and Smith, C. A. (1950). Quantitative studies on the mechanism of gastric secretion in health and disease. Ann. Surg., 132, 626-640.

Ewald, C. A., and Boas, J. (1886). Beiträge zur Physiologie und Pathologie der Verdauung II. Virchows Arch. path. Anat., $104,271$.

Gillespie, I. E., and Grossman, M. I. (1964). Inhibitory effect of secretin and cholecystokinin on Heidenhain pouch responses to gastrin extract and histamine. Gut, 5, 342-345.

Greenlee, H. B., Longhi, E. H., Guerrero, J. D., Nelsen, T. S., El-Bedri, A. L., and Dragstedt, L. R. (1957). Inhibitory effect of pancreatic secretin on gastric secretion. Amer. J. Physiol., 190, 396-402.

Gregory, R. A., and Tracy, H. J. (1959). The action of enterogastrone on gastric secretion. J. Physiol. (Lond.), 149, 58-59P.

Johnson, L. P., and Magee, D. F. (1965). Cholecystokinin-pancreo- zymin extracts and gastric motor inhibition. Surg. Gynec. Obstet., 121, 557-562.

Jorpes, E., and Mutt, V. (1966). Cholecystokinin and pancreozymin, one single hormone? Acta physiol. scand., 66, 196-202, and personal communication.

Magee, D. F., and Nakamura, M. (1966). Action of pancreozymin preparations on gastric secretion. Nature (Lond.), 212, 1487.

Maung Pe Thein, and Schofield, B. (1959). Release of gastrin from the pyloric antrum following vagal stimulation by sham feeding in dogs. J. Physiol. (Lond.), 148, 291-305.

Murat, J. E., and White, T. T. (1966). Stimulation of gastric secretion by commercial cholecystokinin extract. Proc. Soc. exp. Biol. (N.Y.), 123, 593-594.

Mutt, V., and Jorpes, J. E. (1967). Isolation of aspartyl-phenylalanine amide from cholecystokinin-pancreozymin. Biochem. biophys. Res. Commun., 26, 392-397.

Pevsner, L., and Grossman, M. I. (1955). The mechanism of vagal stimulation of gastric acid secretion. Gastroenterology, 28, 493-499.

Preshaw, R. M., and Grossman, M. I. (1965). Comparison of subcutaneous and intravenous administration of pancreatic stimulants. Amer. J. Physiol., 209, 830-810.

Robertson, C. R., Langlois, K., Martin, C. G., Slezak, G., and Grossman, M. I. (1950). Release of gastrin in response to bathing the pyloric mucosa with acetylcholine. Amer. J. Physiol. 163, 27-33 